\title{
Noradrenergic Modulation of Subthalamic Nucleus Activity: Behavioral and Electrophysiological Evidence in Intact and 6-Hydroxydopamine-Lesioned Rats
}

\author{
Pauline Belujon, Erwan Bezard, Anne Taupignon, Bernard Bioulac, and Abdelhamid Benazzouz \\ Centre National de la Recherche Scientifique, Unité Mixte de Recherche 5227, Université Victor Segalen, 33076 Bordeaux Cedex, France
}

\begin{abstract}
The subthalamic nucleus (STN) plays a key role in the pathophysiology of Parkinson's disease. The modulation of the STN by norepinephrine, however, is unknown. The present study aims at characterizing the effects of systemic administration of noradrenergic agents on locomotor activity and on in vivo extracellularly recorded STN neuronal activity in intact and 6-hydroxydopamine (6-OHDA)-lesioned rats. Using selective agonists and antagonists of $\alpha 1$ and $\alpha 2$ adrenergic receptors (ARs), we show that STN neurons have functional $\alpha 1$ and $\alpha 2$-AR controlling STN firing with an impact on locomotor activity. We further demonstrate that those systemic effects are supported, at least in part, by a direct modulation of STN neuronal activity, using patch-clamp recordings of STN neurons in brain slices. These findings support the premise that hypokinesia is associated with an increased STN neuronal activity, and that improvements of parkinsonian motor abnormalities are associated with a decrease in STN activity. Our data challenge assumptions about the role of $\alpha 1$-AR and $\alpha 2$-AR in the regulation of STN neurons in both intact and 6-OHDA-lesioned rats and further ground the rationale for using $\alpha 2$-AR noradrenergic antagonists in Parkinson's disease, albeit via an unexpected mechanism.
\end{abstract}

Key words: norepinephrine (noradrenergic); subthalamic nucleus; Parkinson's disease; locomotor activity; extracellular recordings; 6-hydroxydopamine

\section{Introduction}

Parkinson's disease (PD) is a neurological disorder characterized by a progressive degeneration of nigral dopaminergic neurons projecting to the striatum (Ehringer and Hornykiewicz, 1960). However, other neurotransmitter systems are affected as well, such as norepinephrine (NE) (Forno, 1996). Indeed, neurodegeneration of the locus ceruleus (LC), the principal source of noradrenergic projections in the brain (Chan-Palay and Asan, 1989; Chan-Palay, 1991), is another landmark of the disease that is thought to play a role in akinesia (Narabayashi, 1983), freezing (Mizuno et al., 1994), tremor (Yamazaki et al., 1979), and also in nonmotor symptoms such as depression (Chan-Palay and Asan, 1989) and diminished vigilance (Stern et al., 1984). The search for nondopaminergic agents for treating PD has unraveled a potential role for NE. Thus, blocking the $\alpha 2$-adrenergic receptor $(\alpha 2$ AR), mainly an inhibitory autoreceptor (Starke, 1972; Langer, 1974), has been shown to positively modulate parkinsonian-like motor abnormalities. $\alpha 2$-AR antagonists blocked tremor and rigidity induced by reserpine in the rat (Colpaert, 1987) and po-

\footnotetext{
Received Dec. 22, 2006; revised June 7, 2007; accepted July 7, 2007.

This work was supported by the University Victor Segalen, the Centre National de la Recherche Scientifique (CNRS), and the Institut Fédératif de Recherche (Institut National de la Santé et de la Recherche Médicale No. 8; CNRS No 13). P.B. was supported by a fellowship from the Ministère de I'Education Nationale, de la Recherche et de la Technologie. We thank Sandra Dovero for her technical support and Anthony A. Grace for critical reading.

Correspondence should be addressed to Dr. Abdelhamid Benazzouz, Centre National de la Recherche Scientifique Unité Mixte de Recherche 5227, Université Victor Segalen, 146 rue Léo-Saignat, 33076 Bordeaux Cedex, France. E-mail: Abdelhamid.Benazzouz@u-bordeaux2.fr.

D01:10.1523/JNEUROSCI.2583-07.2007

Copyright $\odot 2007$ Society for Neuroscience $\quad 0270-6474 / 07 / 279595-12 \$ 15.00 / 0$
}

tentiated ipsilateral circling induced by the dopamine (DA) releasing agent amphetamine and the contralateral circling induced by the dopamine agonist apomorphine in the unilateral 6-hydroxydopamine (6-OHDA)-lesioned rat (Mavridis et al., 1991; Chopin et al., 1999). These agents also improved parkinsonian motor abnormalities in the 1-methyl-4-phenyl-1,2,3,6tetrahydropyridine (MPTP)-treated monkey (Colpaert et al., 1991; Bezard et al., 1999) and preserved antiparkinsonian effects of L-3,4-dihydroxyphenylalanine (L-DOPA) while decreasing L-DOPA-induced dyskinesia (Gomez-Mancilla and Bedard, 1993).

However, the pharmacological evidence is poorly supported by anatomical studies that only reveal a minor noradrenergic innervation of the basal ganglia from LC (Parent et al., 1995). In addition to the striatum, the most heavily innervated structure is the subthalamic nucleus (STN) (Boyajian et al., 1987; Canteras et al., 1990; Parent and Hazrati, 1995; Wang et al., 1996). The STN has been shown to play a key role in PD pathophysiology by the disorganization of its neuronal activity (Bergman et al., 1994; Hassani et al., 1996; Ni et al., 2001c). Because lesion (Bergman et al., 1990), high frequency stimulation (Benazzouz et al., 1993), and pharmacological inhibition (Baron et al., 2002) of the STN improved parkinsonian motor abnormalities in MPTP-treated monkey and in PD patients (for review, see Gross et al., 1999), we hypothesized that a part of the antiparkinsonian effects of $\alpha 2-\mathrm{AR}$ antagonists could be mediated by a direct action on STN neurons.

The present study aimed at investigating the regulation of STN neuronal activity in the intact and 6-OHDA-lesioned rat 
model of PD. Because very little information is available on noradrenergic control of STN neuronal activity (Arcos et al., 2003), we investigated the effects of $\alpha 1-\mathrm{AR}$ and $\alpha 2$-AR agonists and antagonists during locomotor activity of intact and 6-OHDAlesioned rats and extracellular single unit activity of STN neurons in both experimental conditions after systemic administration of drugs. Assumptions about the direct effects of these agents were also examined in rat brain slices using patch-clamp recording technique, and actual anatomical localization of $\alpha 1-\mathrm{AR}$ and $\alpha 2$-AR was confirmed using immunohistochemistry.

\section{Materials and Methods}

Animals. Adult male Wistar rats, weighing 280-380 g, were used for behavioral and in vivo electrophysiological experiments. Animals were provided by the "Centre d'Elevage Depré" (Saint Doulchard, France) and arrived at least 1 week before use. They were housed five per cage under artificial conditions of light (light/dark cycle; lights on at 7:00 A.M.), temperature $\left(24^{\circ} \mathrm{C}\right)$, and humidity $(45 \%)$ with food and water available ad libitum. All animal experiments were performed in accordance with the European Communities Council Directive of 24 November 1986 (86/609/EEC).

6-OHDA injection. As described previously (Tai et al., 2003), $30 \mathrm{~min}$ before surgery, animals were injected intraperitoneally with pargyline ( 5 mg/kg; Sigma, Saint Quentin Fallavier, France) and desipramine (25 $\mathrm{mg} / \mathrm{kg}$; Sigma), both dissolved in $0.9 \%$ sodium chloride and injected at a volume of $5 \mathrm{ml} / \mathrm{kg}$ body weight. Rats were placed in a stereotaxic frame (Kopf, Unimecanique, France) under chloral hydrate anesthesia (400 $\mathrm{mg} / \mathrm{kg}$, i.p.; Sigma). Each animal received a unilateral injection of $2.5 \mu \mathrm{l}$ of $6-\mathrm{OHDA}(5 \mathrm{mg} / \mathrm{ml}$ in sterile $\mathrm{NaCl}, 0.9 \%$; Sigma) with $0.01 \%$ ascorbic acid into the right medial forebrain bundle at coordinates $2.8 \mathrm{~mm}$ posterior to bregma, $2 \mathrm{~mm}$ lateral to the midline, and $8.4 \mathrm{~mm}$ below the skull according to the brain atlas of Paxinos and Watson (1996). The 6-OHDA injection was made over a 5 min period using a $10 \mu \mathrm{l}$ Hamilton microsyringe. At the end of each injection, the syringe needle was left in place for an additional $5 \mathrm{~min}$ and then withdrawn slowly to prevent reflux of the solution.

Open-field locomotor activity. Spontaneous horizontal locomotion, vertical activity (or rearing), and stereotyped movements were measured using a photoelectric actimeter (Actitrack; Panlab, Barcelona, Spain), as described previously (Dulawa et al., 1999), 4 weeks after the surgery. The apparatus consisted of a transparent cage that was connected to a photoelectric cell. Light beams detected movement, and the total locomotor activity of each rat was recorded over two sessions of $10 \mathrm{~min}$ each day. All testing in the actimeter was done in an isolated room between 8:00 A.M. and 1:00 P.M. and consisted of three phases for each group of rats, intact and 6-OHDA-lesioned rats. In phase A, spontaneous locomotor activity was recorded during five consecutive days (days 1-5; two times for 10 min each), $30 \mathrm{~min}$ after intraperitoneal injection of $\mathrm{NaCl} 0.9 \%$ each day. Between-session habituation was analyzed by comparing behavior in the actimeter on day 4 versus that on day 5 . The first session of 10 min was considered the daily habituation. Only the locomotor activity recorded during the second session of $10 \mathrm{~min}$ was used for data analysis. In phase $B$, for noradrenergic manipulation (all drugs purchased from Sigma), idazoxan $(\alpha 2$-AR antagonist; $1 \mathrm{mg} / \mathrm{kg})$ or prazosin ( $\alpha 1$-AR antagonist; 1 $\mathrm{mg} / \mathrm{kg}$ ) was injected (intraperitoneally) on the sixth day, $30 \mathrm{~min}$ before placement into the actimeter, and behavior was measured for two sessions of $10 \mathrm{~min}$. Guanabenz ( $\alpha 2$-AR agonist; $1 \mathrm{mg} / \mathrm{kg}$ ) or cirazoline ( $\alpha 1$-AR agonist; $0.05 \mathrm{mg} / \mathrm{kg}$ ) was injected the eighth day as described. In phase $\mathrm{C}$, for a postchallenge test of spontaneous locomotor activity, $1 \mathrm{~d}$ after noradrenergic injection, rats were again re-exposed to the actimeter $30 \mathrm{~min}$ after intraperitoneal injection of $0.9 \% \mathrm{NaCl}$ (days 7 and 9). Statistical analyses were done using Prism (GraphPad Software, San Diego, CA). Values were compared using the Wilcoxon matched-pairs signed ranks test and the Mann-Whitney $U$ test for paired and unpaired values, respectively.

Drugs. Drugs were chosen on the basis of their different affinity for their preferential receptors. In the rat brain, idazoxan and guanabenz show a high affinity for all $\alpha 2$-AR (Ki, 1.63 and 5.8, respectively) (Boya- jian et al., 1987). Idazoxan also shows affinity for serotonin $1 \mathrm{~A}\left(5-\mathrm{HT}_{1 \mathrm{~A}}\right)$ and I2-imidazoline receptors but in a lower extent (Ki, 145 and 30.2, respectively) (Fozard et al., 1987; Molderings et al., 1987). In a similar manner, prazosin and cirazoline show high selectivity for $\alpha 1-\mathrm{AR}(\mathrm{Ki}$, 0.36 and 5.88, respectively) (Bogeso et al., 1988; Scheer et al., 2000). Doses for systemic injection of noradrenergic drugs were selected on the basis of a detailed literature search, showing a significant effect on spontaneous locomotion in rats (Wellman and Davies, 1992; Mathe et al. 1996; Chopin et al., 1999) and followed by search-of-dose investigations aiming at defining a dose producing behavioral effects without sideeffects (data not shown).

Extracellular recordings. Extracellular single-unit recordings were made in rats anesthetized with urethane $(1.2 \mathrm{~g} / \mathrm{kg}$, i.p.). Recordings were done in intact and 6-OHDA-lesioned rats 4 weeks after surgery as reported previously (Tai et al., 2003). Single glass micropipette electrode (impedance, 8-12 M $\Omega$ ) was filled with $4 \%$ Pontamine sky blue in $3 \mathrm{M}$ $\mathrm{NaCl}$ and then placed into the right STN according to the coordinates given in the brain atlas (Paxinos and Watson, 1996) (anteroposterior, 3.8 $\mathrm{mm}$ posterior to bregma; lateral, $2.5 \mathrm{~mm}$ from the midline; dorsal, $6.8-$ $8.2 \mathrm{~mm}$ from the dura). Extracellular neuronal activity was amplified, bandpass-filtered $(300-3000 \mathrm{~Hz})$ using a preamplifier (Neurolog system; Digitimer, Hertfordshire, UK), displayed on an oscilloscope, and transferred via a Powerlab interface (AD Instruments, Oxfordshire, UK) to a computer equipped with Chart 5 software (AD Instruments). Only neuronal activity with a signal-to-noise ratio $>3: 1$ was recorded and used for additional investigation. Basal firing of STN neurons was recorded for 30 min before drug injection to ascertain the stability of the discharge activity. All noradrenergic agents were injected intraperitoneally. Injection of $0.9 \% \mathrm{NaCl}$ was used as drug control. At the end of each session, the recording site was marked by electrophoretic injection (Iso DAM 80; WPI, Hertfordshire, UK) of Pontamine sky blue through the micropipette at a negative current of $20 \mu \mathrm{A}$ for $7 \mathrm{~min}$.

Data analysis. The activity of each STN neuron was analyzed with a spike discriminator using a spike histogram program (AD Instruments, Charlotte, NC), and firing parameters were calculated using Neuroexplorer program (AlphaOmega, Nazareth, Israel). Firing rates of baseline spontaneous neuronal activity of intact rats were then compared with those of 6-OHDA-lesioned rats using Student's $t$ test. Firing rates, before and after drug injection, were compared with a two-way ANOVA with repeated measures followed by the Fisher's least significant difference (protected $t$ ) test. Firing patterns were analyzed using the method developed by Kaneoke and Vitek (1996) as described previously (Boraud et al., 1998; Tai et al., 2003) and compared using a $\chi^{2}$ test, as has also been described previously (Ni et al., 2001a,c; Tai et al., 2003). Parameters of burst firing (number of bursts per second, burst duration, and intraburst frequency) before and after drug injection were compared with a oneway ANOVA with repeated measures followed by the Dunnett's test.

Validation of experimental PD model. Selected animals for final analysis went through a series of validation steps that were all mandatory for final inclusion. The displayed $n$ refers to this final inclusion.

Prior to behavioral investigations and electrophysiological recordings, the effectiveness of the nigrostriatal pathway lesion was checked using the test of contralateral rotational behavior induced by apomorphine. All rats were given a subcutaneous injection of apomorphine $(0.05 \mathrm{mg} / \mathrm{kg}$, dissolved in $0.9 \% \mathrm{NaCl}$; Sigma) 1 week after surgery and placed individually into a $30 \mathrm{~cm}$ diameter round cylinder. The number of turns was counted under visual control, $15 \mathrm{~min}$ after the injection of apomorphine. The rotation rate retained as indicating a good lesion was $>20$ turns per $5 \mathrm{~min}$. All rats used in this study turned consistently toward the side contralateral to the side of the lesion of $>30$ turns per $5 \mathrm{~min}$.

After completion of experiments, fresh-frozen brains were cryostatcut into coronal $20 \mu \mathrm{m}$ sections for further validation of the extent of lesion using striatal dopamine transporter (DAT) binding and of the location of recording track into the STN as described previously (Tai et al., 2003). To this aim, acetylcholine esterase staining was used to determine the location of the Pontamine sky blue dots marking the recording sites in each structure. Only those brains in which the location of the Pontamine sky blue dot was clearly visible in the STN were used for data analysis. 
DAT binding procedure was performed as described previously (Bezard et al., 2001). After purification, $\left[{ }^{125} \mathrm{I}\right](\mathrm{E})-\mathrm{N}$-(3-iodoprop-2-enyl)$2 \beta$-carboxymethyl-3 $\beta$-( $4^{\prime}$-methylphenyl) nortropane (PE2I) was obtained in a no-carrier-added form with a specific activity of $2000 \mathrm{Ci} /$ $\mathrm{mmol}$ and stored in ethanol at $-20^{\circ} \mathrm{C}$, a temperature at which it remains stable for 1 month. Sections were incubated for $90 \mathrm{~min}$ at $25^{\circ} \mathrm{C}$ with 100 pм [ $\left.{ }^{125} \mathrm{I}\right]$ PE2I in pH 7.4 phosphate buffer (in mu: $10.14 \mathrm{Nah}_{2} \mathrm{PO}_{4}, 137$ $\mathrm{NaCl}, 2.7 \mathrm{KCl}$, and $\left.1.76 \mathrm{KH}_{2} \mathrm{PO}_{4}\right)$. After incubation, all sections were then washed twice for $20 \mathrm{~min}$ in phosphate buffer at $4^{\circ} \mathrm{C}$ and dried at room temperature. They were then exposed to $\beta$-radiation-sensitive film (Hyperfilm $\beta$-max; GE Healthcare, Buckingamshire, UK) in x-ray cassettes, for $3 \mathrm{~d}$, for autoradiographic assessment of the radioactivity bound to regions of interest. The optical density was then measured with an image analysis system (Densirag V. D2.00; Biocom, Les Ulis, France) and averaged for each right and left striatum in each animal. The binding of the lesion side was expressed as percentage of binding of the intact side, and only rats presenting a $95-100 \%$ DAT loss in the striatum were retained for data analysis.

\section{In vitro patch-clamp recordings}

Slice preparation. Experiments were performed as described previously (Baufreton et al., 2003), with the exception that inhibitors of fast synaptic transmission were not used, to enable possible actions of noradrenergic drugs on both neurons and neuronal afferents within STN. Briefly, recordings were made using the blind patch-clamp technique in the wholecell configuration and in current-clamp mode on neurons in $400-\mu \mathrm{m}-$ thick midbrain coronal slices, at room temperature. The Krebs' solution contained the following (in mM): $124 \mathrm{NaCl}, 26 \mathrm{NaHCO}_{3}, 3.6 \mathrm{KCl}, 1.3$ $\mathrm{MgCl}_{2}, 2.4 \mathrm{CaCl}_{2}, 1.25$ HEPES, and 10 glucose, $\mathrm{pH} 7.4$, bubbled with $95 \% \mathrm{O}_{2}$ and $5 \% \mathrm{CO}_{2}$. Pipettes were filled with a solution containing the following (in mM): $140 \mathrm{~K}$-gluconate, $11 \mathrm{EGTA}, 10 \mathrm{HEPES}, 1 \mathrm{CaCl}_{2}, 2$ ATP-Mg, and $0.4 \mathrm{Na}-\mathrm{GTP}$, with osmolarity between 280 and $300 \mathrm{mOsm}$, and $\mathrm{pH}$ adjusted to 7.25 . Access resistance $(\sim 20 \mathrm{M} \Omega)$ was monitored regularly. Junction potential was $-13 \mathrm{mV}$ (Baufreton et al., 2001); the voltage error was corrected off-line.

Drugs. All noradrenergic agents were prepared as stock solutions in $\mathrm{H}_{2} \mathrm{O}$ and stored at $-80^{\circ} \mathrm{C}$. They were diluted in the oxygenated Krebs' solution and delivered by means of a gravity-feed system (HSSE-2; ALA Scientific Instruments, Sega Electronique, Paris, France) composed of two capillaries positioned just above the patch pipette.

Data collection and analysis. Data were recorded and analyzed using pClamp 9.2 software (Molecular Devices, Foster City, CA), Origin 6.1 (Microcal, Northampton, MA), and Prism (GraphPad Software, San Diego, CA). Because plateau potentials and postinhibitory rebound bursts differed from one neuron to another (Baufreton et al., 2003; Hallworth et al., 2003; Wang et al., 2006), each neuron served as both control and test. After a period of 3-5 min used to evaluate access resistance, membrane parameters, pattern of firing at zero current level, and stability of recording, plateau potentials and postinhibitory rebound bursts were activated using four to six incremented current steps. Negative holding current injection $(-50$ to $-100 \mathrm{pA})$ was used to hyperpolarize the membrane potential to approximately $-75 \mathrm{mV}$. A protocol of two successive current steps (one negative, to activate a resistance capacity nonregenerative response, and a positive one, activating a robust plateau potential) was then repetitively given with a $20 \mathrm{~s}$ period. When the bath medium contained TTX, 30-40 s periods were used. A noradrenergic agent was perfused after a 5 min control period, and perfusion was maintained until a stable, maximal effect was reached. Plateau potentials and postinhibitory rebound bursts were then recorded again using the same four to six incremented current steps as in the predrug period. Care was taken to perform these test recordings using the same holding current as that used for the control recordings. Wash was then initiated. Indexes of burst potency (i.e., the duration and surface of the regenerative response, the number of action potentials per response, as well as the firing frequency during the response) were measured off-line. Membrane potential, holding current, and input resistance also were registered off-line. Spike amplitude, half-duration, overshoot and threshold, and afterhyperpolarization amplitude, measured off-line from one to five action potential waveform(s) per neuron, were also registered. All values were compared using the Wilcoxon matched-pairs signed ranks test for paired values. Values of $p<0.05$ were considered significant. Percentage changes in duration and number of action potentials are shown using box plots for graphic presentation of the data because of the small sample sizes.

\section{Immunohistochemistry of $\alpha 1$ - and $\alpha 2-A R$}

Four intact rats were perfused transcardially with $100 \mathrm{ml}$ of saline followed by $200 \mathrm{ml}$ of a fixative solution containing $2 \%$ paraformaldehyde and $0.2 \%$ picric acid in $0.1 \mathrm{M}$ phosphate buffer, $\mathrm{pH}$ 7.4. Brains were dissected out and soaked overnight at $4^{\circ} \mathrm{C}$ in phosphate buffer containing $20 \%$ sucrose. Forty-five micrometer sections were cut in a vibratome (Leica, Rueil-Malmaison, France) and processed for immunohistochemistry. After washing in PBS, free-floating sections were incubated overnight at room temperature, with the primary antibody anti- $\alpha 1 \mathrm{a}$ adrenergic (1/500; Santa Cruz Biotechnology, Santa Cruz, CA) or anti- $\alpha 2 \mathrm{c}$ adrenergic (1/1000; US Biological, Euromedex, Souffelweyersheim, France), diluted in PBS containing 1/500 BSA and 0.3\% Triton X-100. After the PBS washes, sections previously incubated with the primary antibody were incubated with rabbit anti-goat IgG (Sigma, St. Quentin Fallavier, France) at 1:500 in PBS containing $1 / 500$ BSA and $0.3 \%$ Triton $\mathrm{X}-100$ during $1 \mathrm{~h}$ at room temperature. All sections were then rinsed with PBS and incubated with Envision + system HRP-labeled polymer antirabbit (Dako, High Wycombe, UK). After three PBS rinses, binding of antibodies were revealed using diaminobenzidine (DAB) (peroxydase substrate kit; Vector Laboratories, Burlingame, CA), which gives a black precipitate when enhanced with nickel.

\section{Results}

Spontaneous horizontal locomotion, rearing, and stereotyped movements were measured using an actimeter 4 weeks after the surgery. Preliminary studies showed that after $3 \mathrm{~d}$ of habituation, the behavior of the animals was stable, indicating that the rats were accustomed to their test environment. As shown previously (Fornaguera et al., 1994; Miklyaeva et al., 1995), the only parameter that differs significantly from intact to lesioned rats is the vertical activity. Indeed, the mean rearing score was significantly lower in 6-OHDA-lesioned rats (19.5 \pm 4.0) when compared with intact animals $(40.9 \pm 6.0$; Mann-Whitney test, $p<0.01)$. No significant difference was observed for the horizontal activity $(1353 \pm 157$ in intact vs $1019 \pm 163$ in lesioned rats; $p=0.14)$ or for the stereotypic activity scores $(1472 \pm 83$ in intact vs $1265 \pm$ 96 in lesioned rats; $p=0.11$ )

The effects of noradrenergic agents on locomotor activity of intact rats are shown in Figure $1 A$. Prazosin ( $\alpha 1$-AR antagonist), cirazoline ( $\alpha 1$-AR agonist), and guanabenz ( $\alpha 2$-AR agonist) injections significantly decreased horizontal activity, stereotypy, and rearing compared with saline injection (Wilcoxon test, $p<$ $0.05 ; n=7)$. However, idazoxan $(\alpha 2$-AR antagonist $)$ injection significantly increased these three parameters compared with saline injection (Wilcoxon test, $p<0.05 ; n=7$ ).

Effects of noradrenergic agents on locomotor activity of 6-OHDA-lesioned rats are shown in Figure $1 B$. As in intact rats, administration of prazosin and guanabenz in 6-OHDA-lesioned rats significantly decreased horizontal activity, stereotypy, and rearing compared with saline injections (Wilcoxon test, $p<0.05$; $n=6)$. Cirazoline injection had no effect on these three parameters ( $p=0.56$ for stereotypy and rearing; $p=0.44$ for horizontal activity; $n=6$ ). Idazoxan was the only agent that induced a significant increase of stereotypy and rearing (Wilcoxon test, $p<$ $0.05 ; n=6$ ) and a trend toward increased horizontal activity, which failed to reach significance $(p=0.0625 ; n=6)$. Administration of idazoxan reversed the significant decrease of vertical activity. Indeed, there was no more significant difference between the number of rearing after the administration of idazoxan in lesioned rats and after saline injection in intact rats (MannWhitney test; $p=0.73$ ). 


\section{Effect of noradrenergic agents on the firing rate of STN neurons}

To establish whether systemic administration of noradrenergic agents induced modulation of STN neuronal activity, we examined extracellular single-unit activity of STN neurons in both experimental conditions: in intact and 6-OHDA-lesioned rats. A total of 50 neurons were recorded in the STN in both groups ( $n=46$ rats): 24 intact rats (26 cells) and 22 lesioned rats ( 24 cells). In intact rats, firing rates of STN neurons ranged from 1.9 to 14.2 spikes/s with a mean of $5.5 \pm 0.6$ spikes/s $(n=26)$. In lesioned rats, firing rates of STN neurons ranged from 2.4 to 28.7 spikes/s with a mean of $7.8 \pm 1.2$ spikes/s $(n=24)$. This firing rate was not significantly different from that of intact rats $(p=0.1)$ as reported previously (Ni et al., 2001b,c; Tai et al., 2003). In intact and 6-OHDA-lesioned rats, STN neurons exhibited three different firing patterns. In control rats, the majority of units $(62 \% ; n=16$ of 26$)$ exhibited a regular or irregular firing pattern. Ten of $26(38 \%)$ exhibited a burst firing pattern. In lesioned rats, the majority of units ( $71 \% ; n=17$ of 24 ) exhibited a burst firing pattern, and only $29 \%$ exhibited a regular or irregular firing pattern ( $n=7$ of 24). Proportions of regular and burst patterns were significantly different between intact and lesioned rats $(Z$ test; $p<0.05$ ) as reported previously (Hassani et al., 1996; Ni et al., 2001b,c; Tai et al., 2003).

Responses of STN neurons to different noradrenergic agents are shown in Figures 2 and 3. Any nonspecific effect resulting from the intraperitoneal injection of saline was tested in a control experiment using intact rats. Saline was injected under the same conditions as for noradrenergic agents. No change was observed in the firing activity of STN neurons $(p=0.99 ; n=4)$ (data not shown).

\section{Effect of $\alpha 1$-AR agonist, cirazoline}

In intact as well as in lesioned rats, cirazoline $(0.05 \mathrm{mg} / \mathrm{kg})$ exerted different effects on STN neurons (Fig. 2, left). Figure 2, A1 and $A 2$, shows the typical excitatory response of a subthalamic neuron after injection of cirazoline in an intact rat. Cirazoline injection increased the firing rate of the majority of STN neurons (four of six neurons in intact rats and three of five neurons in 6-OHDA-lesioned rats; $F=4.68$; $\mathrm{p}<0.01$ ). In intact rats, this effect occurred $10 \mathrm{~min}$ after the injection and was maintained for $1 \mathrm{~h}$ (for example, $+47.4 \pm 7 \%$, at $35 \mathrm{~min} ; p<0.05$ ) (Fig. $2 \mathrm{B1}$ ). In lesioned rats, this effect occurred $10 \mathrm{~min}$ after the injection and was maintained for $<30 \mathrm{~min}$ (for example, $+104 \pm 100 \%$, at 25 min; $p<0.05$ ) (Fig. 2 B2). In intact and lesioned rats, a minority of STN neurons was significantly inhibited after injection of this agent $(F=8.93 ; p<0.01$; two of six neurons and two of five neurons, respectively). In intact rats, this effect occurred $30 \mathrm{~min}$ after the injection and was maintained for $20 \mathrm{~min}$ (Fig. 2B1) $(-45.5 \pm 35 \%$, at $35 \mathrm{~min} ; p<0.05)$. In lesioned rats, the effect occurred $20 \mathrm{~min}$ after the injection and was maintained for 30 min (Fig. 2 B2) ( $-63 \pm 14 \%$, at $25 \mathrm{~min} ; p<0.01)$. The 6-OHDA lesion had no effect on the time course after the injection of
B
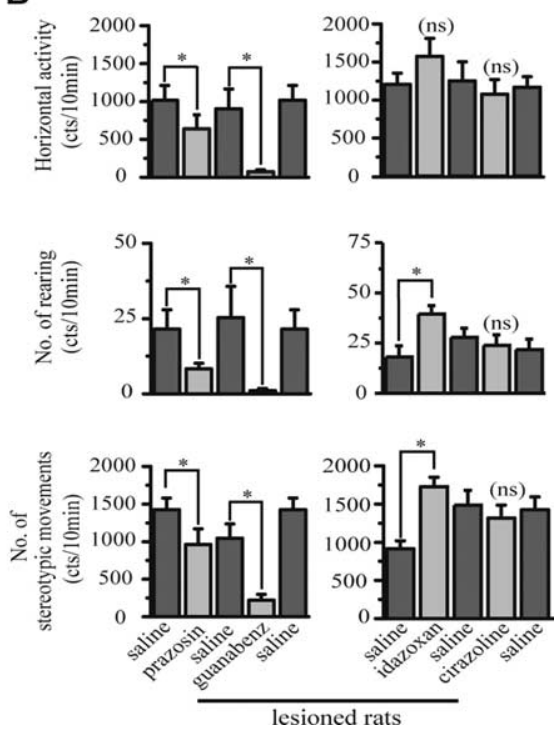

intact rats
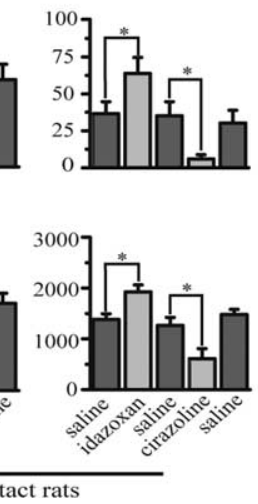

A

Figure 1. Effect of systemic injection of noradrenergic agents on locomotor activity of intact and 6-hydroxydopamine-lesioned rats. Each group of intact and lesioned rats received only two noradrenergic drugs separated by saline injection. $\boldsymbol{A}$, Thirteen rearing and stereotypic movements but has no effect on horizontal activity. Prazosin and guanabenz significantly decreased all

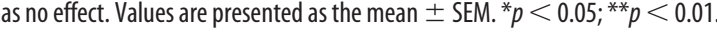

cirazoline in the cases of decrease or increase of the firing rate $(F=1.12, p=0.4$, and $F=1.14, p=0.36$, respectively $)$.

\section{Effect of $\alpha 1-A R$ antagonist, prazosin}

In both intact and 6-OHDA-lesioned rats, prazosin $(1 \mathrm{mg} / \mathrm{kg})$ induced a clear inhibitory effect on the population of STN neurons sampled ( $F=17.9 ; p<0.0001$ ) (Fig. 2 , right). Figure 2, C1 and $C 2$, shows the typical response of a subthalamic neuron in an intact rat. In intact rats, all of the tested neurons $(n=7)$ showed a significant decrease in their firing rate $(-68.7 \pm 7 \%$, at $35 \mathrm{~min}$; $p<0.01)$, compared with the basal level. The effect occurred 10-20 min after the injection and was maintained for $>2 \mathrm{~h}$ (Fig. 2 D1). In rats with 6-OHDA lesions, all STN neurons $(n=6)$ were also inhibited by the administration of prazosin $(-44.5 \pm 10 \%$, at $35 \mathrm{~min} ; p<0.01$ ), compared with the basal level. As observed in intact rats, the effect occurred 10-20 min after the injection and was maintained for $>2 \mathrm{~h}$ (Fig. 2D2). No recovery to the basal level was obtained. The 6-OHDA lesion had no effect on the time course after the injection of prazosin $(F=1.7 ; p=0.1)$ compared with intact rats.

\section{Effect of $\alpha 2$-AR agonist, guanabenz}

In both intact and lesioned rats, guanabenz $(1 \mathrm{mg} / \mathrm{kg})$ induced a clear excitatory effect on the population of STN neurons examined (Fig. $3 A)(F=7.3 ; p<0.01)$. In intact rats, all of the neurons tested $(n=7)$ showed a significant increase in their firing rate $(64.7 \pm 23 \%$, at $25 \mathrm{~min} ; p<0.01)$, compared with the basal level. The effect occurred $20 \mathrm{~min}$ after the injection and was maintained for $20 \mathrm{~min}(p<0.01)$. One hour after the injection, the basal level was recovered for all neurons (Fig. 3B1). In rats with 6 -OHDA lesions, all STN neurons $(n=5)$ also were excited, but to a less extent, by administration of guanabenz $(47.3 \pm 12 \%$, at 25 min; $p<0.01$ ) compared with the basal level. The effect occurred $20 \mathrm{~min}$ after the injection, and the basal level was recovered $40 \mathrm{~min}$ after (Fig. 3B2). The 6-OHDA lesion induced a sig- 
A1

Before

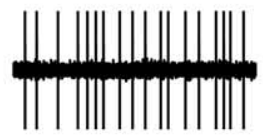

$1200 \mathrm{mV}$ After cirazoline injection

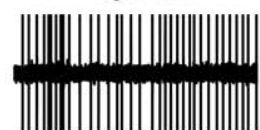

A2

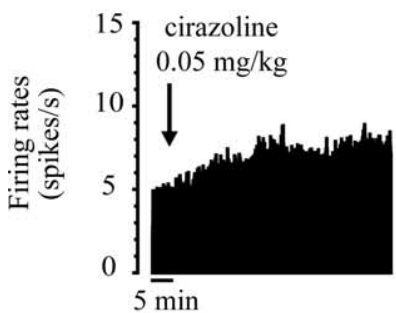

B1

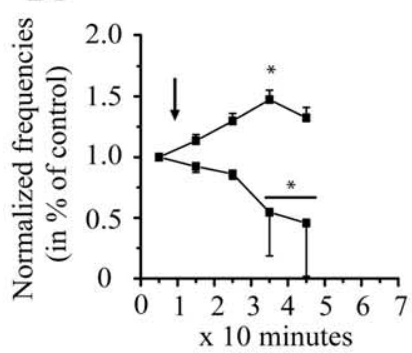

D1

$\mathrm{C} 2$
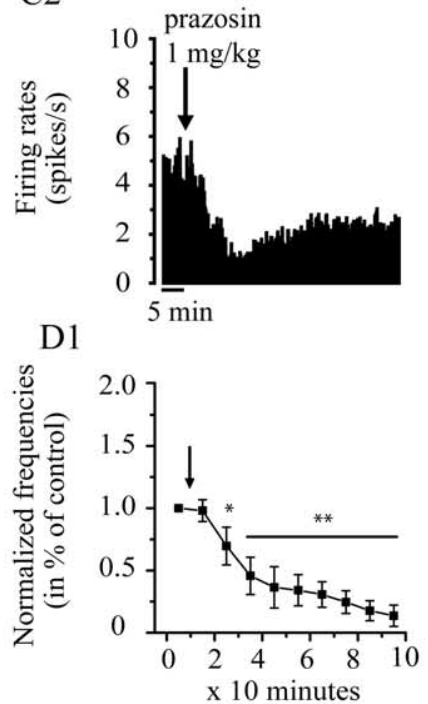

intact rats

B2

D2
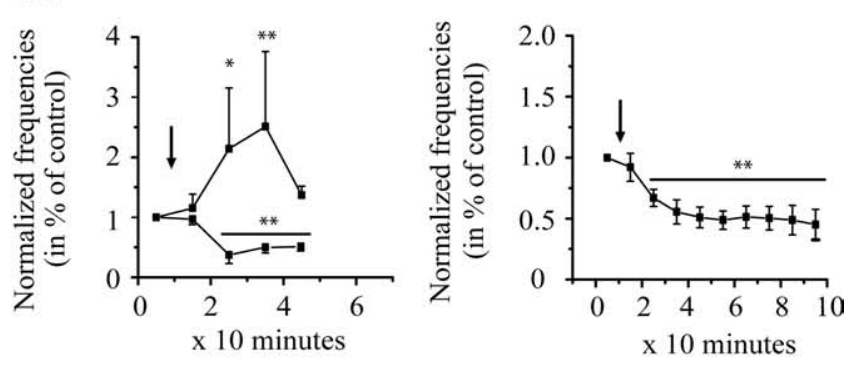

lesioned rats

Figure 2. Effects of intraperitoneal injection of cirazoline $(0.05 \mathrm{mg} / \mathrm{kg}$, left) and prazosin (1 $\mathrm{mg} / \mathrm{kg}$, right) on the firing rate of STN neurons in vivo. $A, C$, Representative examples of subthalamic neurons showing the effect of cirazoline and prazosin, respectively: section of recordings $(\boldsymbol{A 1}, \boldsymbol{C} 1)$ and firing rate histogram $(\boldsymbol{A 2}, \mathbf{C})$ showing the excitatory and the inhibitory effect of cirazoline and prazosin, respectively, in an intact rat. $\boldsymbol{B}$, Cirazoline induced inhibitory and excitatory effects on STN neuron firing rates in intact $(n=7 ; \boldsymbol{B} 1)$ and lesioned $(n=6 ; \boldsymbol{B} 2)$ rats. $D$, Prazosin inhibits the firing rate of all STN neuron firing rates also in both groups (intact, $n=$ 6, D1; lesioned rats, $n=5, \mathbf{D 2}$ ). Arrows indicate the time at which agents were administrated. The mean of firing rate was counted every 10 min after the injection. ${ }^{*} p<0.05$; ${ }^{* *} p<0.01$.

nificantly different time course after the injection of guanabenz $(F=3.3 ; p<0.05)$ compared with intact rats.

Effect of $\alpha 2$-AR antagonist, idazoxan

In both intact and lesioned rats, idazoxan $(1 \mathrm{mg} / \mathrm{kg})$ provoked a clear inhibitory effect on all of the STN neurons tested (Fig. 3C) $(F=19.974 ; p<0.0001)$, but no difference in the effect was
A1

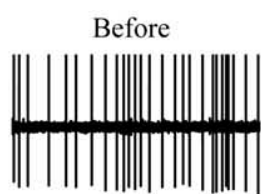

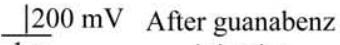

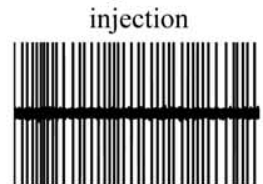

C1

Before

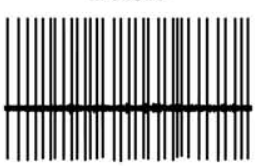

$200 \mathrm{mV} \quad$ After idazoxan injection

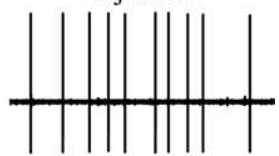

A2

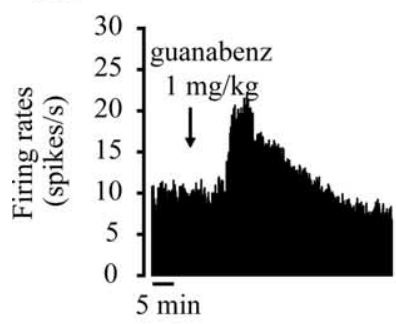

$\mathrm{C} 2$

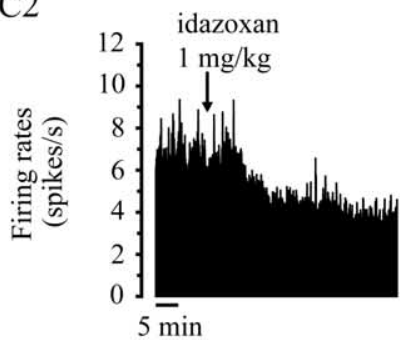

D1
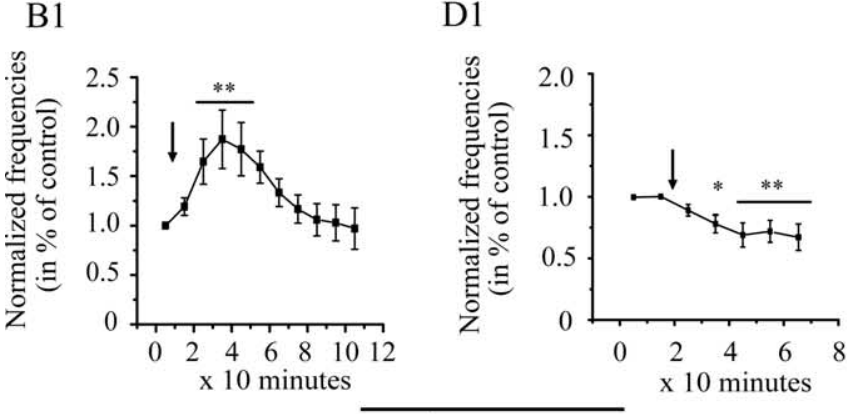

intact rats

B2

D2
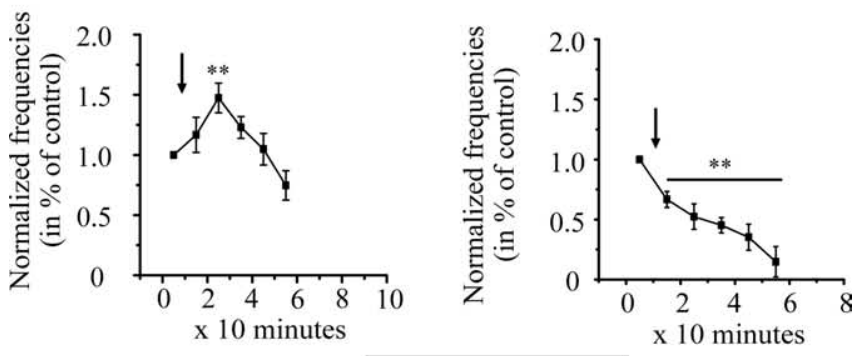

lesioned rats

Figure 3. Effects of intraperitoneal injection of guanabenz ( $1 \mathrm{mg} / \mathrm{kg}$; left) and idazoxan (1 $\mathrm{mg} / \mathrm{kg}$; right) in vivo. $\boldsymbol{A}, \boldsymbol{C}$, Section of recordings (A1, C1) and firing rate histogram (A2, (2) showing the excitatory and inhibitory effects of guanabenz and idazoxan, respectively, in an intact rat. $\boldsymbol{B}$, Injection of guanabenz increases the firing rate of all STN neurons in intact $(n=5$; B1) and lesioned $(n=7 ; \boldsymbol{B} 2)$ rats. Idazoxan decreases the firing rate of all STN neurons in both groups (intact, $n=7, \mathbf{D 1}$; lesioned rats, $n=5, \mathbf{D 2}$ ). Arrows indicate the time at which agents were administrated. ${ }^{*} p<0.05 ;{ }^{* *} p<0.01$

observed between these groups $(F=2.85 ; p=0.12)$. In intact rats, all neurons $(n=5)$ showed a significant decrease in their firing rate ( $31 \pm 9 \%$, at $45 \mathrm{~min} ; p<0.01$ ). This effect occurred 20 min after the injection, and no recovery to the basal level was observed (Fig. 3D1). In lesioned rats, all neurons $(n=6)$ were also significantly inhibited, but to a higher extent, by administration of idazoxan $(54.8 \pm 6 \%$, at $25 \mathrm{~min} ; p<0.01)$. This effect occurred $10 \mathrm{~min}$ after the injection, and no recovery to the basal level was observed (Fig. 3D2). The 6-OHDA lesion induced a 
Table 1. Changes in duration, number of spikes, firing frequency of plateau potentials, and rebound bursts induced by the application of the four noradrenergic agents

\begin{tabular}{|c|c|c|c|c|c|c|c|c|}
\hline & \multicolumn{4}{|c|}{ Plateau potentials (\% change) } & \multicolumn{4}{|c|}{ Rebound bursts (\% change) } \\
\hline & Duration & $\begin{array}{l}\text { Number of } \\
\text { spikes }\end{array}$ & Frequency & & Duration & $\begin{array}{l}\text { Number of } \\
\text { spikes }\end{array}$ & Frequency & \\
\hline Cirazoline & $+111 \pm 40^{*}$ & $+376 \pm 224^{*}$ & $+126 \pm 46^{*}$ & $n=7$ & $+44 \pm 8^{*}$ & $+89 \pm 40$ & $+23 \pm 20$ & $n=7$ \\
\hline Prazosin & $-48 \pm 13^{*}$ & $-56 \pm 16^{*}$ & $-39 \pm 10$ & $n=6$ & $-37 \pm 5^{*}$ & $-54 \pm 15^{*}$ & $-40 \pm 10$ & $n=6$ \\
\hline Guanabenz & $+65 \pm 11^{*}$ & $+553 \pm 200^{*}$ & $+318 \pm 118^{*}$ & $n=7$ & $+8 \pm 5$ & $+14 \pm 11$ & $+17 \pm 5$ & $n=5$ \\
\hline Idazoxan & $-48 \pm 5^{* *}$ & $-70 \pm 7^{* *}$ & $-41 \pm 13^{*}$ & $n=10$ & $-48 \pm 7^{*}$ & $-85 \pm 8^{*}$ & $-80 \pm 13^{*}$ & $n=6$ \\
\hline
\end{tabular}

The values are normalized to the average values in control. ${ }^{*} p<0.05 ;{ }^{* *} p<0.01$.

significantly different time course after the injection of idazoxan $(F=3.52 ; p<0.01)$ compared with intact rats.

\section{Effect of idazoxan on burst pattern of STN neurons}

As shown above, idazoxan is the only noradrenergic agent tested that induced an increase of the locomotor activity in 6-OHDAlesioned rats. Moreover, this agent induced a clear decrease in firing rate of STN neurons of lesioned rats. Because burst pattern in STN neurons is described as an indicator of the pathological situation in PD, we analyzed burst parameters before and after administration of idazoxan in 6-OHDA-lesioned rats. Six of seven neurons $(85.7 \%)$ tested for idazoxan experiments have shown a burst pattern before injection. Proportion of neurons with burst firing pattern was not significantly different after injection of this agent $(p=1)$. Idazoxan had no significant effect on number of bursts per second and on burst duration $(p=0.72$ and $p=0.4$, respectively; $n=6$ ). However, idazoxan induced a significant decrease of intraburst frequency $20 \mathrm{~min}$ after the injection $(p<0.05 ; n=6)$. In fact, intraburst frequency was $34.7 \pm$ 1.5 spikes/s before versus $24.5 \pm 2.6$ spikes/s $20 \mathrm{~min}$ after the administration of idazoxan.

\section{Effect of noradrenergic agents on evoked burst firing of STN neurons in slices}

The results described above were obtained in vivo with intraperitoneal injections of noradrenergic agents. We used the same four noradrenergic agents on rat coronal brain slices containing STN to test whether the effect of the drugs on the firing activity of subthalamic neurons in vivo resulted from a direct effect on neurons or neuronal afferents within STN.

Burst firing is displayed spontaneously by only a small fraction of STN neurons in vitro. A larger proportion of STN neurons are nevertheless burst-competent. Burst-competent neurons give specific responses, called plateau potentials, to short depolarizing current pulses given at hyperpolarized levels (Beurrier et al., 1999; Baufreton et al., 2003; Kass and Mintz, 2006). These responses always outlast the stimuli and resemble evoked bursts. In addition, burst-competent neurons produce postinhibitory rebound bursts when stimulated by hyperpolarizing steps (Beurrier et al., 1999; Baufreton et al., 2003; Hallworth and Bevan, 2005; Wang et al., 2006). Because burst firing is a hallmark of PD (Bergman et al., 1994), we investigated whether $\alpha 1$ - and $\alpha 2$-AR agonists or antagonists interfered with burst competency. To this end, we evoked plateau potentials and rebound bursts and analyzed three indexes of burst efficacy: duration, number of action potentials in, and firing frequency of plateau potentials and postinhibitory rebound bursts. The changes induced by the four noradrenergic agents are summarized in Table 1.

Figure 4 presents the action of the $\alpha 1$-AR-specific agonist and antagonist, cirazoline and prazosin. The duration of plateau potentials was significantly ( $p<0.05 ; n=7)$ increased by cirazoline, because the mean control value was $331.3 \pm 93.5 \mathrm{~ms}$, whereas after continued perfusion of cirazoline $(1 \mu \mathrm{M})$, mean duration was $657.3 \pm 111.2 \mathrm{~ms}$ (Fig. $4 \mathrm{~A}$ ). This was accompanied by an increase in the number of spikes (control, $8.0 \pm 4.4$ spikes per plateau potentials; cirazoline, $22.5 \pm 12.1$ spikes per plateau potentials; $p<0.05 ; n=7)$. The duration of the postinhibitory rebound bursts evoked by hyperpolarizing pulses was also increased (control, $840 \pm 101 \mathrm{~ms}$; cirazoline, 1180. $\pm 135 \mathrm{~ms} ; p<$ $0.05 ; n=7$ ), but the number of spikes per rebound burst was not changed significantly (control, $19.8 \pm 7.4$; cirazoline, $33.6 \pm 14$; $p=0.06 ; n=7$ ). Indeed, the increase in the number of spikes per plateau potential was not only caused by an increase in duration but also to a significant increase in intraburst firing rate. A firing rate of $14.2 \pm 6.0 \mathrm{~Hz}$ was observed in control versus $26.3 \pm 11.0$ $\mathrm{Hz}$ after continued perfusion of cirazoline ( $p<0.05 ; n=7)$. Such a change in the intraburst firing rate was not observed for rebound bursts (control, $20.3 \pm 6.3 \mathrm{~Hz}$; cirazoline, $23.4 \pm 7.8 \mathrm{~Hz}$; $p=0.4 ; n=7)$. Cirazoline did not significantly alter the membrane potential and the input resistance of the same neuron sample. Membrane potential and input resistance values were $-84.0 \pm 2.7$ versus $-80.5 \pm 0.6 \mathrm{mV}(p>0.05 ; n=7)$ and $173 \pm$ 11 versus $175 \pm 12 \mathrm{M} \Omega(p=0.4 ; n=7)$, respectively. Furthermore, action potential waveform was not modified. Neither spike amplitude, half duration, overshoot and threshold, nor afterhyperpolarization amplitude were changed. Potentiation was always reversed by wash-out (data not shown).

The $\alpha 1$-AR antagonist prazosin was also active on some parameters of plateau potentials and postinhibitory rebound bursts. Prazosin $(10 \mu \mathrm{M})$ induced a marked decrease in duration of both plateau potentials and rebound bursts (Fig. $4 B$ ). In control, plateau potentials lasted for $451 \pm 77 \mathrm{~ms}$ and rebound bursts for $997 \pm 123 \mathrm{~ms}$, whereas the corresponding values in prazosin were $260 \pm 82 \mathrm{~ms}$ and $618.9 \pm 80 \mathrm{~ms}$, respectively $(p<0.05 ; n=$ $6)$. There was also a decrease in the number of spikes per response (control, $14.4 \pm 4.0$ and $58.0 \pm 13.0$, respectively; prazosin, $6.8 \pm$ 3.5 and $27.3 \pm 12.5$, respectively; $p<0.05 ; n=6$ ). The intraburst firing rate remained unchanged (plateau potentials, $30.8 \pm 8.0 \mathrm{vs}$ $16.7 \pm 6.0 \mathrm{~Hz}$ in prazosin, $p=0.3, n=6$; rebound burst, $53 \pm 7$ $\mathrm{Hz}$ vs prazosin, $36 \pm 14 \mathrm{~Hz}, p=0.16, n=6)$. In the same way as cirazoline, prazosin did not interfere significantly with membrane potential, input resistance, or spike waveform. Its action was always reversed by wash-out (data not shown).

Figure 5 shows the results of similar experiments using the $\alpha 2$-AR agents guanabenz and idazoxan. Guanabenz, the $\alpha 2$-AR agonist $(1 \mu \mathrm{M})$, exhibited subtle effects. It increased the duration of plateau potentials (control, $379.6 \pm 98.0 \mathrm{~ms}$; guanabenz, $629.5 \pm 193.0 \mathrm{~ms} ; p<0.05 ; n=7)$, the number of spikes per plateau potential (control, $6.0 \pm 3.4$; guanabenz, $14.7 \pm 6.0 ; p<$ $0.05 ; n=7$ ) and intraburst firing rate (control, $10.3 \pm 5.0 \mathrm{~Hz}$; guanabenz, $21.8 \pm 8.0 \mathrm{~Hz} ; p<0.05 ; n=7)$. In contrast, the postinhibitory rebound bursts evoked by hyperpolarizing pulses did not change after guanabenz application, because neither their duration $(912 \pm 128$ vs $924 \pm 130 \mathrm{~ms}$ in guanabenz; $p=0.6 ; n=$ 
A

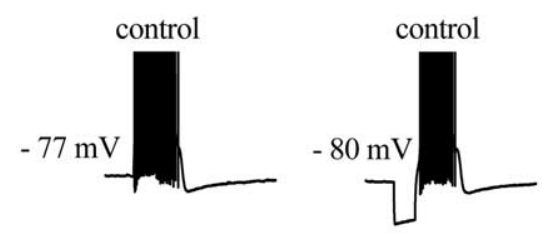

B

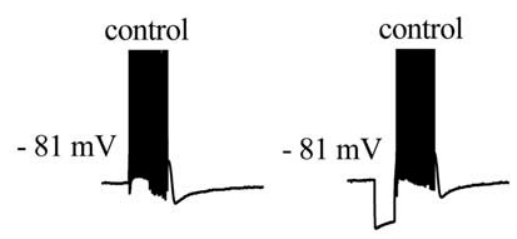

$\underset{1 \mathrm{~s}}{\mathrm{~J}} 20 \mathrm{mV}$
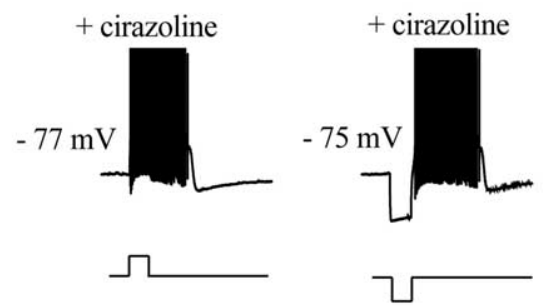

(7)

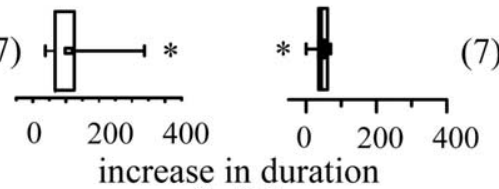

(in \%)
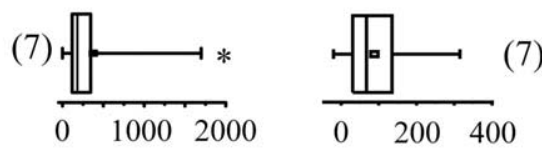

increase in spike number

(in \%)
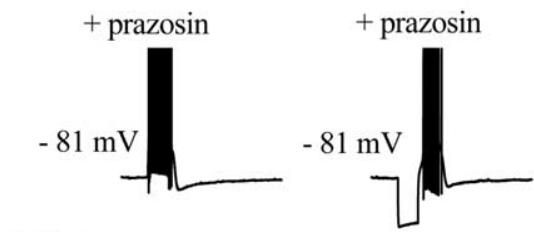

I $200 \mathrm{pA}$

(6)

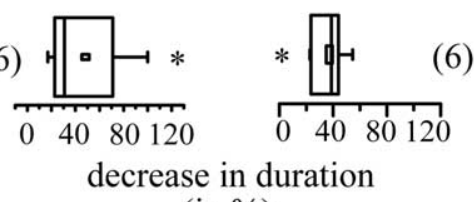
(in \%)
(6)

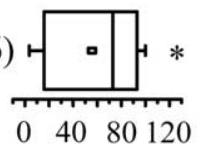

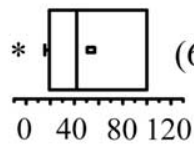

decrease in spike number (in $\%$ )
Figure 4. Action of the $\alpha 1$-AR agonist cirazoline $(1 \mu \mathrm{m} ; \boldsymbol{A})$ and the $\alpha 1$-AR antagonist prazosin $(10 \mu \mathrm{m} ; \boldsymbol{B})$ on burst-competent neurons in STN in vitro. Depolarizing (left) or hyperpolarizing (right) stimuli trigger plateau potentials or postinhibitory rebound bursts, respectively. Top traces show a representative example of these two regenerative responses. Both responses are potentiated by cirazoline and inhibited by prazosin (bottom traces). Spikes are truncated at $+10 \mathrm{mV}$. Box plots present the changes in two indexes of burst potency, duration of, and number of spikes in the regenerative responses. ${ }^{*} p<0.05$

agents had no major effect on neuron baseline properties. Membrane potential, input resistance, and action potential waveform in predrug condition were not significantly different from that measured when the action on plateau potential and postinhibitory rebound burst was maximal (data not shown).

\section{Identity of $\alpha$-AR in the STN}

The observation that both $\alpha 1$ - and $\alpha 2$-AR agonists and antagonists have a clear effect on STN neurons in slices prompted us to define localization of both receptors. $\alpha 1 \mathrm{a}-\mathrm{AR}$ is mostly expressed postsynaptically in STN neurons, as well as cortical neurons or hippocampal neurons (Fig. $6 A-C)$. Expression of $\alpha 2 \mathrm{c}-\mathrm{AR}$ is found on fibers localized in the STN, cortex, the dorsal part of premamillary nucleus, and the parasubthalamic nucleus (Fig. 6D-F). The presence of $\alpha 2$-AR postsynaptically in STN cell bodies was not found. These results are in agreement with previous studies that classified $\alpha$-AR in two groups, $\alpha 1$ and $\alpha 2$-, based on anatomical localization, whereby $\alpha 1$-AR were located on postsynaptic membranes and $\alpha 2$-AR on presynaptic nerve terminals (Langer, 1974; Starke et al., 1974).

\section{Idazoxan has a presynaptic action}

Our immunohistochemical results thus suggest that the inhibitory action of idazoxan described above is not attributable to a direct action on subthalamic neurons but rather to a presynaptic action. To functionally test that idazoxan alters neurotransmitter release from presynaptic terminals, we inhibited synaptic transmission in brain slices by perfusion

5) nor number of spikes (control, $17 \pm 4$; guanabenz, $22.2 \pm 8.0$; $p=0.2 ; n=5$ ) were significantly modified (Fig. $5 A$, right). Potentiation was never reversed by wash-out (data not shown).

The $\alpha 2$-AR antagonist idazoxan $(10 \mu \mathrm{M})$ reduced all indexes of burst competency, because it produced a significant reduction in the three parameters of burst potency. The mean decrease in plateau potential duration was $48 \pm 5 \%$ (Fig. $5 B$, left) (control, $788.7 \pm 190.5 \mathrm{~ms}$; idazoxan, $444 \pm 147 \mathrm{~ms} ; p<0.01 ; n=10)$. Rebound burst duration decreased by $45.8 \pm 8.0 \%$ (control, $1364 \pm 156 \mathrm{~ms}$; idazoxan, $720 \pm 82 \mathrm{~ms} ; p<0.05 ; n=6$ ) (Fig. $5 B$, right). This was accompanied by a decrease in the number of spikes (plateau potentials: control, $29 \pm 10$; idazoxan, $13 \pm 6$; $p<$ $0.01 ; n=10$; rebound bursts: control, $57.9 \pm 15.0$; idazoxan, $6.2 \pm 4.0 ; p<0.05 ; n=6)$ and by a decrease in intraburst firing frequency of plateau potentials as well as rebound bursts. Mean intraburst firing frequency of plateau potentials was $33.0 \pm 6.0$ $\mathrm{Hz}$ in control and $26 \pm 7 \mathrm{~Hz}$ after perfusion of idazoxan $(p<$ $0.05 ; n=10)$. Mean discharge frequency of rebound bursts decreased from $21.6 \pm 6.0$ to $12.2 \pm 8.0 \mathrm{~Hz}(p<0.05 ; n=6)$. Its action was always reversed by wash-out (data not shown).

Measurements of membrane potential and input resistance, as well as spike waveform analysis revealed that the two $\alpha 2$-AR of TTX. It has been shown that plateau potentials do not rely on synaptic transmission (Beurrier et al., 1999; Baufreton et al., 2001; Zhu et al., 2004). Nevertheless, glutamate release presumably controls plateau potential potency, because agonists and antagonists of metabotropic glutamate receptors interfere with plateau potential and burst-firing activation (Awad et al., 2000; Zhu et al., 2004, 2005). In the presence of TTX, long-lasting plateau potentials were readily activated by depolarizing current steps. However, in all neurons tested, TTX occluded the action of idazoxan. Coapplication of TTX (1 $\mu \mathrm{M})$ and idazoxan $(10 \mu \mathrm{M})$ for $10 \mathrm{~min}$ was without effect (Fig. $7 B$ ), whereas application of idazoxan alone markedly reduced plateau potentials in $3 \mathrm{~min}$ (Fig. 7A). Our neuron sample did not show any significant change in the duration of plateau potential, as illustrated by the statistical distributions in Figure $7 C$. The average values of plateau potential duration of $1849 \pm 436$ and $1930 \pm 429 \mathrm{~ms}$ were obtained from TTX alone and TTX plus idazoxan recordings, respectively. Indeed, idazoxan in the presence of TTX did not induce any change in the regenerative conductance underlying plateau potentials, because plateau potential surface remained unaltered (Fig. 7B) 


\section{Discussion}

The present work shows that noradrenergic modulation of locomotor activity in intact and 6-OHDA-lesioned rats is mediated, at least in part in the STN, through presynaptic $\alpha 2$-AR and postsynaptic $\alpha 1$ AR. They establish that the behavioral improvement mediated by the $\alpha 2$-AR antagonist idazoxan on postural activity of lesioned animals is related to a decrease in the firing rate of STN neurons and that idazoxan may act, at least partially, through direct effect on the STN.

\section{Effects of noradrenergic agents on locomotor activity}

Interestingly, most of the tested noradrenergic agents had a clear inhibitory effect on the locomotor activity parameters with comparable effects in both intact and lesioned rats (except for cirazoline in lesioned rats) (Fig. 1) in agreement with previous studies (Antonelli et al., 1991; Wellman and Davies, 1992; Mathe et al., 1996). In contrast, the $\alpha 2$-AR antagonist idazoxan increased the spontaneous activity of both intact and lesioned rats (i.e., displaying an antiparkinsonian activity), in keeping with previous reports showing that several $\alpha 2$-AR antagonists increase motor activity under normal conditions and improve motor functions in experimental and human parkinsonism (Kalkman et al., 1997; Bezard et al., 1999; Villegier et al., 2003).

\section{NE innervation of STN}

The STN is an acknowledged key structure in the basal ganglia as emphasized by the remarkable efficacy of therapeutics aiming at controlling its pathological activity in PD (Bergman et al., 1990; Benazzouz et al., 1993). Although primarily under the control of pallidal and cortical afferents, STN is also modulated by DA (Ni et al., 2001b; Baufreton et al., 2003; Cragg et al., 2004) and 5-HT (Stanford et al., 2005; Xiang et al., 2005). However, NE modulation of STN is not documented (but see Arcos et al., 2003), although noradrenergic fibers arising from LC have been shown in the STN (Canteras et al., 1990; Parent and Hazrati, 1995). Whereas the "excitatory" $\alpha 1$-AR are thought to be located on postsynaptic membrane and the "inhibitory" $\alpha 2$-AR on presynaptic nerve terminals (Langer, 1974; Starke et al., 1974; Lakhlani et al., 1996), their actual distribution in the STN was not documented. The present immunohistochemical data suggest that $\alpha 1$-ARs are located within the STN cell bodies, whereas $\alpha 2$ ARs are expressed on STN afferent fibers (Fig. 6).

Effects of $\alpha 1$ noradrenergic agents on STN neuronal activity The $\alpha 1$-AR agonist impaired motor behavior in intact rats but had no effect in lesioned animals. Cirazoline has both excitatory and inhibitory effects on electrical activity of STN neurons both in intact and lesioned rats (Fig. 2). As behavioral and electrophys- iological data are not consistent, a direct $\alpha 1$-AR-mediated modulation of STN is likely not entirely responsible for the behavioral outcome, suggesting a role for other structures. For instance, stimulation of $\alpha 1$-AR has a direct excitatory effect on SNc DA neurons (Grenhoff et al., 1995) that, in return, exert a direct excitatory modulation of STN neurons (Cragg et al., 2004). $\alpha 1$ ARs are highly expressed in the dorsal raphe nucleus that sends 5-HT projections to the STN (Mori et al., 1985; Lavoie and Parent, 1990). 5-HT induces both excitation and inhibition in the STN (Stanford et al., 2005). Discrepancies in cirazoline effect on STN electrical activity in vivo could be explained by such indirect actions. Accordingly, in slices, cirazoline induced only an excitatory effect by acting on $\alpha 1$-AR localized on cell bodies. Indeed, we observed a potent increase in duration and intraburst frequency of plateau potentials. Spontaneous bursts and evoked plateau potentials are caused by the same $\mathrm{Ca}^{2+}$ and $\mathrm{Ca}^{2+}$-activated con- 


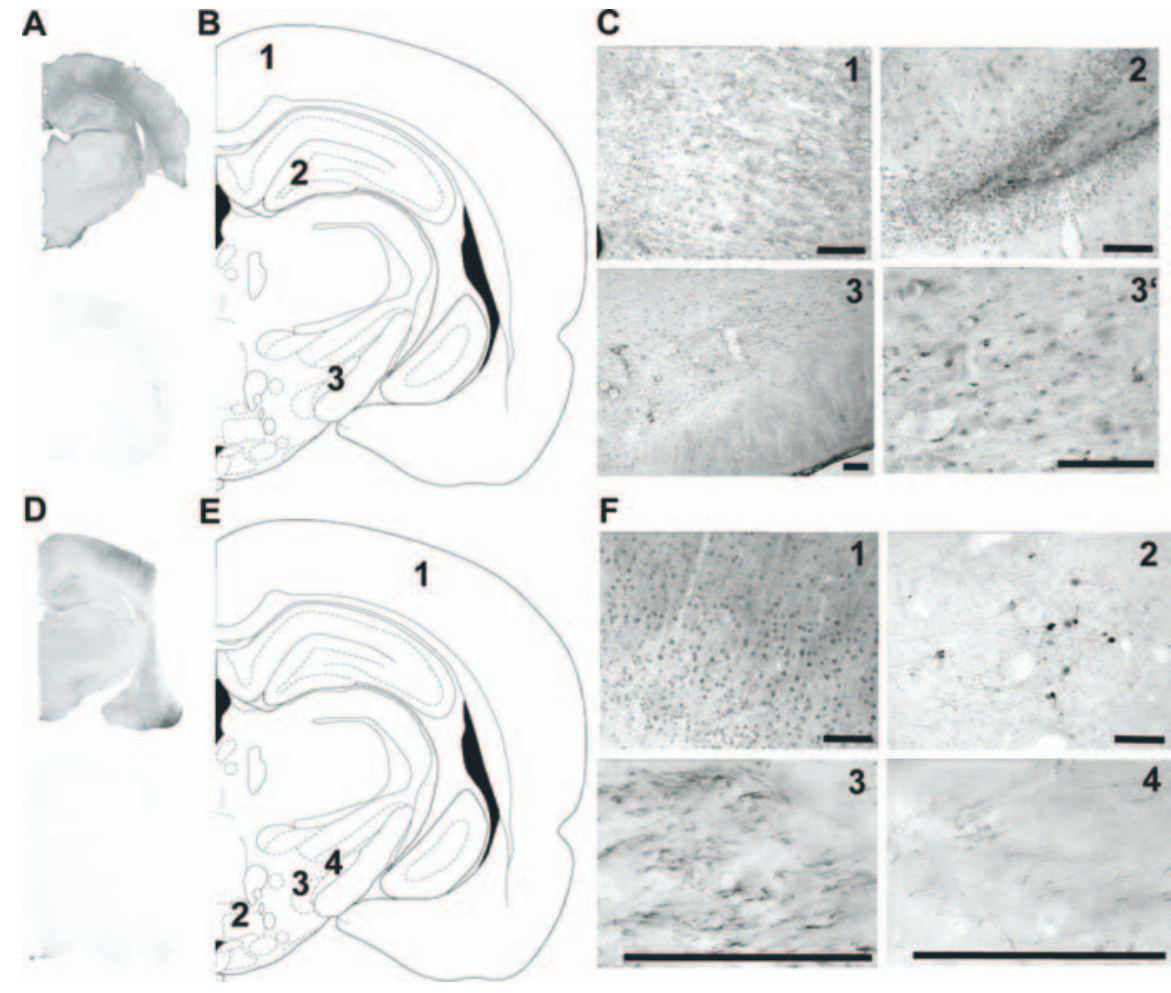

Figure 6. Localization of $\alpha 1$ - and $\alpha 2$-ARs. Microphotographs illustrating representative immunochemistry of $\alpha 1 a-A R s(\boldsymbol{A}-\boldsymbol{C})$ and $\alpha 2$ C-ARs $(\boldsymbol{D}-\boldsymbol{F})$. Receptors were revealed by nickel-DAB immunochemistry that gives a black precipitate $(\boldsymbol{A}, \boldsymbol{D}$, top to $\boldsymbol{A}, \boldsymbol{D}$, bottom illustrate negative control). $\boldsymbol{B}, \boldsymbol{E}$, Schematic of coronal sections (right hemisphere) of the rat brain showing structures that were used for the comparison of immunochemistry. $\boldsymbol{B}, \boldsymbol{C}, \alpha 1 \mathrm{a}-\mathrm{ARs}$; (1) retrospenial agranular cortex, (2) polymorph layer of the dentate gyrus, (3) subthalamic nucleus, ( $\left.3^{\prime}\right)$ magnification of (3). Brain sections correspond to the atlas of Paxinos and Watson (1996); $\boldsymbol{E}, \boldsymbol{F}, \alpha 2 c-A R s: ~(1)$ parietal association cortex, (2) premamillary nucleus dorsal part, (3) parasubthalamic nucleus, (4) subthalamic nucleus. Scale bar, $50 \mu \mathrm{m}$.

ductances (Beurrier et al., 1999; Otsuka et al., 2001). Activation of $\alpha 1$-AR by cirazoline may induce an increase of intracellular $\mathrm{Ca}^{2+}$ through activation of a Gq-protein, thus inducing $\mathrm{Ca}^{2+}$ channel activation.

Contrary to the $\alpha 1$-AR agonist effects, the antagonist prazosin induced a clear inhibitory effect both on spontaneous locomotion and on electrical activity of STN neurons (Fig. 2), again raising a paradoxical result. Indeed a decrease in STN neuronal activity should parallel an increased motor activity (Baron et al., 2002; Mehta and Chesselet, 2005). The known hypotensive action of prazosin could be ruled out, because it occurs at doses 10-fold higher than that used here (Sommermeyer et al., 1995). Therefore, the diminished locomotor activity may represent a functional consequence of blockade of $\alpha 1$-AR elsewhere in the brain. Decreases in STN electrical activity are also observed in slices, indicating that prazosin could indeed act directly on STN neurons. These data also indicate that the only blockade of $\alpha 1$-AR is sufficient to inhibit evoked plateau potentials, underlying a possible baseline activation of these receptors by noradrenalin.

\section{Effects of $\alpha \mathbf{2}$ noradrenergic agents on STN neuronal activity}

The systemic injection of the $\alpha 2$-AR agonist induced an increase in spontaneous activity of STN neurons (Fig. 3). $\alpha 2$-ARs are present on afferents to the STN, a major part of those being GABAergic projections from the pallidum, thereby providing a mean of dampening the inhibitory influence over the STN, resulting into an increased STN activity. Such increased STN out- put enhances the inhibitory output from $\mathrm{SNr}$ to thalamus thereby diminishing the motor output from the cortex to lower motor centers (DeLong, 1990). However, bicuculline microinjection into the STN induces a diminution of sniffing and grooming behaviors but not the immobility score, an index of hypokinesia (Martinez-Price and Geyer, 2002), suggesting that blockade of GABA release alone in STN is not sufficient to explain the inhibition of locomotor activity in intact and lesioned rats. In slices, guanabenz induced a potent increase in duration and intraburst frequency of plateau potentials but no change in parameters of postinhibitory rebound bursts. Because rebound bursts and plateau potentials share at least some common ionic conductances (Beurrier et al., 1999; Otsuka et al., 2001), our results show that guanabenz has an action that differs from that of the other adrenergic agents. Guanabenz thus enhances plateau potentials through intracellular pathways that remain to be determined.

The systemically administered $\alpha 2$-AR antagonist idazoxan potentiated motor activity in both intact and lesioned rats. Such behavioral outcome matches with the inhibitory action on STN electrical activity measured both in vivo (systemic) and in vitro (direct action). Applying the same reasoning as above, it suggests that blocking $\alpha 2$-AR localized on GABAergic pallidal inputs potentiates the inhibitory influence over the STN. Some studies have shown that TTX, which inhibits synaptic transmission, suppressed action potentials but not plateau potentials when a current pulse is applied (Beurrier et al., 1999). In our study, a decrease of plateau potentials by idazoxan is blocked by previous administration of TTX confirming a presynaptic action of idazoxan on $\alpha 2$-AR.

Although the sole direct effect on STN cannot explain the variety of effects of idazoxan, it is striking that in vitro, idazoxan induces a significant decrease in duration of bursts and intraburst firing rate and that in vivo, it decreases the intraburst frequency in lesioned animals. Because firing patterns are not affected, these results underlie the fact that a decrease in the firing frequency with no change in the pattern of neurons is sufficient to improve some parkinsonian symptoms, consistent with the Alexander and Crutcher model (Alexander et al., 1990).

Idazoxan, in addition to its $\alpha 2$-AR antagonist properties, exhibits very mild 5- $\mathrm{HT}_{1 \mathrm{~A}}$ receptor agonist properties (Llado et al., 1996; Sastre-Coll et al., 1999) and also I2-imidazoline agonist properties (Convents et al., 1989). Because I2-imidazoline receptors are expressed in the striatum (Vauquelin et al., 1999) and not in STN, an alternate target could only be the inhibitory postsynaptic 5- $\mathrm{HT}_{1 \mathrm{~A}}$ receptor on STN neurons (Pompeiano et al., 1994; Stanford et al., 2005). However, because idazoxan has a higher potency at $\alpha 2-\mathrm{AR}(\mathrm{Ki}, 1.63 \mathrm{nM}$ ) (Boyajian et al., 1987) than at $5-\mathrm{HT}_{1 \mathrm{~A}}$ receptors (Ki, $145 \mathrm{~nm}$ ) (Fozard et al., 1987) and given the relative low dose we used, it rules out a major role of this receptor in the reported effects. 
A
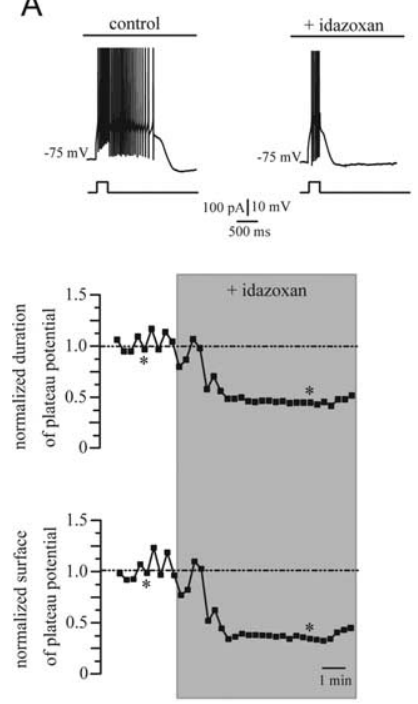

B
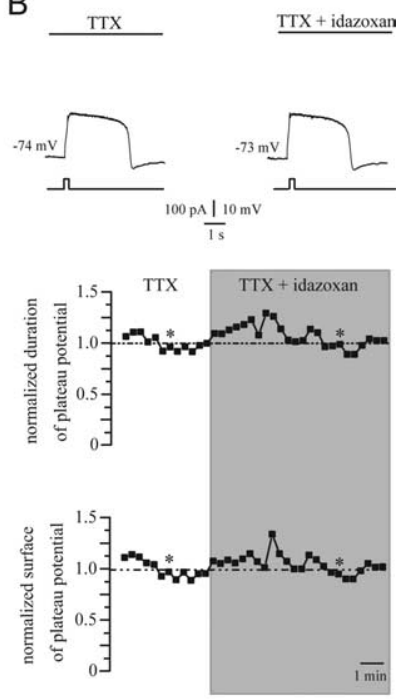

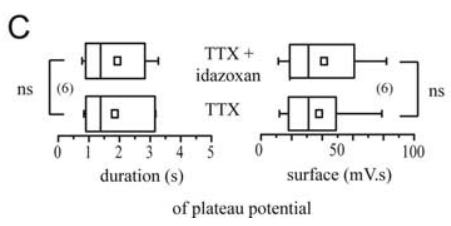

Figure 7. Idazoxan alters synaptic release of neurotransmitter within STN. A, Time course of the action of idazoxan on plateau potential duration and surface. The normalized values of the duration and of the surface of the plateau potentials in a representative experiment are shown. The top traces illustrate the plateau potentials evoked at the time points indicated by the asterisks in the graphs. $\boldsymbol{B}$, Synaptic transmission in brain slices was blocked by perfusion of $1 \mu \mathrm{m}$ TTX. Coapplication of TTX $(1 \mu \mathrm{M})$ and idazoxan $(10 \mu \mathrm{M})$ was without effect. C, Statistical distribution of the values of duration and surface in the neuron sample tested with idazoxan and TTX $(n s ; p>0.05)$. Note that the statistical distribution of the values of durations of plateau potentials in the neuron sample challenged with idazoxan alone is shown Figure $6 B$.

\section{Clinical relevance}

Idazoxan and other $\alpha 2$-AR antagonists improve tremor and rigidity in the reserpinized rat (Colpaert, 1987) and parkinsonian disability in monkey model of PD (Colpaert et al., 1991; Bezard et al., 1999). They also potentiate amphetamine- and apomorphineinduced rotations in unilaterally nigral lesioned rats (Mavridis et al., 1991; Chopin et al., 1999; Haapalinna et al., 2003), prolong the duration of L-DOPA-induced contralateral rotations (Haapalinna et al., 2003), have a potent effect on L-DOPA-induced dyskinesia, and can extend the anti-parkinsonian effect of L-DOPA in MPTP-treated monkeys (Henry et al., 1999; Domino et al., 2003). Incomplete pilot clinical trials suggest that, indeed, such class of drugs reduces bradykinesia and rigidity in parkinsonian patients (Brefel-Courbon et al., 1998) and dyskinesia severity when given in combination with L-DOPA (Brefel-Courbon et al., 1998; Rascol et al., 2001). Results from the double-blind placebo-controlled fipamezole clinical trial are still awaited.

\section{Conclusion}

To date, effects of $\alpha 2$-AR antagonists were thought to result from a striatal modulation of release of the endogenously and/or exogenously formed dopamine. The present study proposes instead that a direct inhibitory action on STN neurons might account for the striking behavioral effects reported in animal models and in PD patients, likely through modulation of GABA release. Moreover, this study provides new insight into the role of noradrenergic receptors in the regulation of STN, giving an important place to the locus ceruleus-noradrenergic system in $\mathrm{PD}$ pathophysiology.

\section{References}

Alexander GE, Crutcher MD, DeLong MR (1990) Basal gangliathalamocortical circuits: parallel substrates for motor, oculomotor, "prefrontal" and "limbic" functions. Prog Brain Res 85:119-146.

Antonelli T, Morari M, Magri A, Bianchi C (1991) Effect of alphaadrenoreceptors in the control of spontaneous motility and morphine withdrawal syndrome. Boll Soc Ital Biol Sper 67:965-971.

Arcos D, Sierra A, Nunez A, Flores G, Aceves J, Arias-Montano JA (2003) Noradrenaline increases the firing rate of a subpopulation of rat subthalamic neurones through the activation of alpha 1-adrenoceptors. Neuropharmacology 45:1070-1079.

Awad H, Hubert GW, Smith Y, Levey AI, Conn PJ (2000) Activation of metabotropic glutamate receptor 5 has direct excitatory effects and potentiates NMDA receptor currents in neurons of the subthalamic nucleus. J Neurosci 20:7871-7879.

Baron MS, Wichmann T, Ma D, DeLong MR (2002) Effects of transient focal inactivation of the basal ganglia in parkinsonian primates. J Neurosci 22:592-599.

Baufreton J, Garret M, Dovero S, Dufy B, Bioulac B, Taupignon A (2001) Activation of GABA(A) receptors in subthalamic neurons in vitro: properties of native receptors and inhibition mechanisms. J Neurophysiol 86:75-85.

Baufreton J, Garret M, Rivera A, de la Calle A, Gonon F, Dufy B, Bioulac B, Taupignon A (2003) $\mathrm{D}_{5}$ (not $\mathrm{D}_{1}$ ) dopamine receptors potentiate burstfiring in neurons of the subthalamic nucleus by modulating an L-type calcium conductance. J Neurosci 23:816-825.

Benazzouz A, Gross C, Feger J, Boraud T, Bioulac B (1993) Reversal of rigidity and improvement in motor performance by subthalamic highfrequency stimulation in MPTP-treated monkeys. Eur J Neurosci 5:382-389

Bergman H, Wichmann T, DeLong MR (1990) Reversal of experimental parkinsonism by lesions of the subthalamic nucleus. Science 249:1436-1438.

Bergman H, Wichmann T, Karmon B, DeLong MR (1994) The primate subthalamic nucleus. II. Neuronal activity in the MPTP model of parkinsonism. J Neurophysiol 72:507-520.

Beurrier C, Congar P, Bioulac B, Hammond C (1999) Subthalamic nucleus neurons switch from single-spike activity to burst-firing mode. J Neurosci 19:599-609.

Bezard E, Brefel C, Tison F, Peyro-Saint-Paul H, Ladure P, Rascol O, Gross CE (1999) Effect of the alpha 2 adrenoreceptor antagonist, idazoxan, on motor disabilities in MPTP-treated monkey. Prog Neuropsychopharmacol Biol Psychiatry 23:1237-1246.

Bezard E, Dovero S, Prunier C, Ravenscroft P, Chalon S, Guilloteau D, Crossman AR, Bioulac B, Brotchie JM, Gross CE (2001) Relationship between the appearance of symptoms and the level of nigrostriatal degeneration in a progressive 1-methyl-4-phenyl-1,2,3,6-tetrahydropyridine-lesioned macaque model of Parkinson's disease. J Neurosci 21:6853-6861.

Bogeso KP, Arnt J, Boeck V, Christensen AV, Hyttel J, Jensen KG (1988) Antihypertensive activity in a series of 1-piperazino-3-phenylindans with potent 5-HT2-antagonistic activity. J Med Chem 31:2247-2256.

Boraud T, Bezard E, Guehl D, Bioulac B, Gross C (1998) Effects of L-DOPA on neuronal activity of the globus pallidus externalis (GPe) and globus pallidus internalis (GPi) in the MPTP-treated monkey. Brain Res 787:157-160.

Boyajian CL, Loughlin SE, Leslie FM (1987) Anatomical evidence for alpha-2 adrenoceptor heterogeneity: differential autoradiographic distributions of $\left[{ }^{3} \mathrm{H}\right]$ rauwolscine and $\left[{ }^{3} \mathrm{H}\right]$ idazoxan in rat brain. J Pharmacol Exp Ther 241:1079-1091.

Brefel-Courbon C, Thalamas C, Peyro-Saint-Paul H, Senard J, Montastuc J, Rascol O (1998) alpha-2 adrenoceptor antagonists-a new approach to Parkinson's disease? CNS Drugs 10:189-207.

Canteras NS, Shammah-Lagnado SJ, Silva BA, Ricardo JA (1990) Afferent connections of the subthalamic nucleus: a combined retrograde and anterograde horseradish peroxidase study in the rat. Brain Res 513:43-59.

Chan-Palay V (1991) Alterations in the locus coeruleus in dementias of Alzheimer's and Parkinson's disease. Prog Brain Res 88:625-630.

Chan-Palay V, Asan E (1989) Alterations in catecholamine neurons of the locus coeruleus in senile dementia of the Alzheimer type and in Parkin- 
son's disease with and without dementia and depression. J Comp Neurol 287:373-392.

Chopin P, Colpaert FC, Marien M (1999) Effects of alpha-2 adrenoceptor agonists and antagonists on circling behavior in rats with unilateral 6-hydroxydopamine lesions of the nigrostriatal pathway. J Pharmacol Exp Ther 288:798-804.

Colpaert FC (1987) Pharmacological characteristics of tremor, rigidity and hypokinesia induced by reserpine in rat. Neuropharmacology 26:1431-1440.

Colpaert FC, Degryse AD, Van Craenendonck HV (1991) Effects of an alpha 2 antagonist in a 20-year-old Java monkey with MPTP-induced parkinsonian signs. Brain Res Bull 26:627-631.

Convents A, Convents D, De Backer JP, De Keyser J, Vauquelin G (1989) High affinity binding of $3 \mathrm{H}$ rauwolscine and $3 \mathrm{H}$ RX781094 to alpha 2 adrenergic receptors and non-stereoselective sites in human and rabbit brain cortex membranes. Biochem Pharmacol 38:455-463.

Cragg SJ, Baufreton J, Xue Y, Bolam JP, Bevan MD (2004) Synaptic release of dopamine in the subthalamic nucleus. Eur J Neurosci 20:1788-1802.

DeLong MR (1990) Primate models of movement disorders of basal ganglia origin. Trends Neurosci 13:281-285.

Domino EF, Ni L, Colpaert F, Marien M (2003) Effects of (+/-)-idazoxan alone and in combination with L-DOPA methyl ester in MPTP-induced hemiparkinsonian monkeys. Receptors Channels 9:335-338.

Dulawa SC, Grandy DK, Low MJ, Paulus MP, Geyer MA (1999) Dopamine $\mathrm{D}_{4}$ receptor-knock-out mice exhibit reduced exploration of novel stimuli. J Neurosci 19:9550-9556.

Ehringer H, Hornykiewicz O (1960) Distribution of noradrenaline and dopamine (3-hydroxytyramine) in the human brain and their behavior in diseases of the extrapyramidal system. Klin Wochenschr 38:1236-1239.

Fornaguera J, Carey RJ, Huston JP, Schwarting RK (1994) Behavioral asymmetries and recovery in rats with different degrees of unilateral striatal dopamine depletion. Brain Res 664:178-188.

Forno LS (1996) Neuropathology of Parkinson's disease. J Neuropathol Exp Neurol 55:259-272.

Fozard JR, Mir AK, Middlemiss DN (1987) Cardiovascular response to 8-hydroxy-2-(di-n-propylamino) tetralin (8-OH-DPAT) in the rat: site of action and pharmacological analysis. J Cardiovasc Pharmacol 9:328-347.

Gomez-Mancilla B, Bedard PJ (1993) Effect of nondopaminergic drugs on L-DOPA-induced dyskinesias in MPTP-treated monkeys. Clin Neuropharmacol 16:418-427.

Grenhoff J, North RA, Johnson SW (1995) alpha 1-adrenergic effects on dopamine neurons recorded intracellularly in the rat midbrain slice. Eur J Neurosci 7:1707-1713.

Gross CE, Boraud T, Guehl D, Bioulac B, Bezard E (1999) From experimentation to the surgical treatment of Parkinson's disease: prelude or suite in basal ganglia research? Prog Neurobiol 59:509-532.

Haapalinna A, Leino T, Heinonen E (2003) The alpha 2-adrenoceptor antagonist atipamezole potentiates anti-Parkinsonian effects and can reduce the adverse cardiovascular effects of dopaminergic drugs in rats. Naunyn Schmiedebergs Arch Pharmacol 368:342-351.

Hallworth NE, Bevan MD (2005) Globus pallidus neurons dynamically regulate the activity pattern of subthalamic nucleus neurons through the frequency-dependent activation of postsynaptic $\mathrm{GABA}_{\mathrm{A}}$ and $\mathrm{GABA}_{\mathrm{B}}$ receptors. J Neurosci 25:6304-6315.

Hallworth NE, Wilson CJ, Bevan MD (2003) Apamin-sensitive small conductance calcium-activated potassium channels, through their selective coupling to voltage-gated calcium channels, are critical determinants of the precision, pace, and pattern of action potential generation in rat subthalamic nucleus neurons in vitro. J Neurosci 23:7525-7542.

Hassani OK, Mouroux M, Feger J (1996) Increased subthalamic neuronal activity after nigral dopaminergic lesion independent of disinhibition via the globus pallidus. Neuroscience 72:105-115.

Henry B, Fox SH, Peggs D, Crossman AR, Brotchie JM (1999) The alpha2adrenergic receptor antagonist idazoxan reduces dyskinesia and enhances anti-parkinsonian actions of L-DOPA in the MPTP-lesioned primate model of Parkinson's disease. Mov Disord 14:744-753.

Kalkman HO, Neumann V, Tricklebank MD (1997) Clozapine inhibits catalepsy induced by olanzapine and loxapine, but prolongs catalepsy induced by SCH 23390 in rats. Naunyn Schmiedebergs Arch Pharmacol 355:361-364.

Kaneoke Y, Vitek JL (1996) Burst and oscillation as disparate neuronal properties. J Neurosci Methods 68:211-223.
Kass JI, Mintz IM (2006) Silent plateau potentials, rhythmic bursts, and pacemaker firing: three patterns of activity that coexist in quadristable subthalamic neurons. Proc Natl Acad Sci USA 103:183-188.

Lakhlani PP, Lovinger DM, Limbird LE (1996) Genetic evidence for involvement of multiple effector systems in alpha $2 \mathrm{~A}$-adrenergic receptor inhibition of stimulus-secretion coupling. Mol Pharmacol 50:96-103.

Langer SZ (1974) Presynaptic regulation of catecholamine release. Biochem Pharmacol 23:1793-1800.

Lavoie B, Parent A (1990) Immunohistochemical study of the serotoninergic innervation of the basal ganglia in the squirrel monkey. J Comp Neurol 299:1-16.

Llado J, Esteban S, Garcia-Sevilla JA (1996) The alpha 2-adrenoceptor antagonist idazoxan is an agonist at 5-HT1A autoreceptors modulating serotonin synthesis in the rat brain in vivo. Neurosci Lett 218:111-114.

Martinez-Price DL, Geyer MA (2002) Subthalamic 5-HT(1A) and 5-HT(1B) receptor modulation of RU 24969-induced behavioral profile in rats. Pharmacol Biochem Behav 71:569-580.

Mathe JM, Nomikos GG, Hildebrand BE, Hertel P, Svensson TH (1996) Prazosin inhibits MK-801-induced hyperlocomotion and dopamine release in the nucleus accumbens. Eur J Pharmacol 309:1-11.

Mavridis M, Colpaert FC, Millan MJ (1991) Differential modulation of $(+)$-amphetamine-induced rotation in unilateral substantia nigralesioned rats by alpha 1 as compared to alpha 2 agonists and antagonists. Brain Res 562:216-224.

Mehta A, Chesselet MF (2005) Effect of GABA(A) receptor stimulation in the subthalamic nucleus on motor deficits induced by nigrostriatal lesions in the rat. Exp Neurol 193:110-117.

Miklyaeva EI, Martens DJ, Whishaw IQ (1995) Impairments and compensatory adjustments in spontaneous movement after unilateral dopamine depletion in rats. Brain Res 681:23-40.

Mizuno Y, Kondo T, Mori H (1994) Various aspects of motor fluctuations and their management in Parkinson's disease. Neurology 44:S29-S34.

Molderings GJ, Fink K, Schlicker E, Gothert M (1987) Inhibition of noradrenaline release via presynaptic 5-HT1B receptors of the rat vena cava. Naunyn Schmiedebergs Arch Pharmacol 336:245-250.

Mori S, Takino T, Yamada H, Sano Y (1985) Immunohistochemical demonstration of serotonin nerve fibers in the subthalamic nucleus of the rat, cat and monkey. Neurosci Lett 62:305-309.

Narabayashi H (1983) Pharmacological basis of akinesia in Parkinson's disease. J Neural Transm Suppl 19:143-151.

Ni Z, Bouali-Benazzouz R, Gao D, Benabid AL, Benazzouz A (2001a) Intrasubthalamic injection of 6-hydroxydopamine induces changes in the firing rate and pattern of subthalamic nucleus neurons in the rat. Synapse 40:145-153.

Ni Z, Gao D, Bouali-Benazzouz R, Benabid AL, Benazzouz A (2001b) Effect of microiontophoretic application of dopamine on subthalamic nucleus neuronal activity in normal rats and in rats with unilateral lesion of the nigrostriatal pathway. Eur J Neurosci 14:373-381.

Ni ZG, Bouali-Benazzouz R, Gao DM, Benabid AL, Benazzouz A (2001c) Time-course of changes in firing rates and firing patterns of subthalamic nucleus neuronal activity after 6-OHDA-induced dopamine depletion in rats. Brain Res 899:142-147.

Otsuka T, Murakami F, Song WJ (2001) Excitatory postsynaptic potentials trigger a plateau potential in rat subthalamic neurons at hyperpolarized states. J Neurophysiol 86:1816-1825.

Parent A, Hazrati LN (1995) Functional anatomy of the basal ganglia. II. The place of subthalamic nucleus and external pallidum in basal ganglia circuitry. Brain Res Brain Res Rev 20:128-154.

Parent A, Cote PY, Lavoie B (1995) Chemical anatomy of primate basal ganglia. Prog Neurobiol 46:131-197.

Paxinos G, Watson C (1996) The rat brain in stereotatic coordinates. San Diego: Academic.

Pompeiano M, Palacios JM, Mengod G (1994) Distribution of the serotonin 5-HT2 receptor family mRNAs: comparison between 5-HT2A and 5-HT2C receptors. Brain Res Mol Brain Res 23:163-178.

Rascol O, Arnulf I, Peyro-Saint Paul H, Brefel-Courbon C, Vidailhet M, Thalamas C, Bonnet AM, Descombes S, Bejjani B, Fabre N, Montastruc JL, Agid Y (2001) Idazoxan, an alpha-2 antagonist, and L-DOPAinduced dyskinesias in patients with Parkinson's disease. Mov Disord 16:708-713.

Sastre-Coll A, Esteban S, Garcia-Sevilla JA (1999) Effects of imidazoline re- 
ceptor ligands on monoamine synthesis in the rat brain in vivo. Naunyn Schmiedebergs Arch Pharmacol 360:50-62.

Scheer A, Costa T, Fanelli F, De Benedetti PG, Mhaouty-Kodja S, Abuin L, Nenniger-Tosato M, Cotecchia S (2000) Mutational analysis of the highly conserved arginine within the Glu/Asp-Arg-Tyr motif of the alpha(1b)-adrenergic receptor: effects on receptor isomerization and activation. Mol Pharmacol 57:219-231.

Sommermeyer H, Frielingsdorf J, Knorr A (1995) Effects of prazosin on the dopaminergic neurotransmission in rat brain. Eur J Pharmacol 276:267-270.

Stanford IM, Kantaria MA, Chahal HS, Loucif KC, Wilson CL (2005) 5 -Hydroxytryptamine induced excitation and inhibition in the subthalamic nucleus: action at 5-HT(2C), 5-HT(4) and 5-HT(1A) receptors. Neuropharmacology 49:1228-1234.

Starke K (1972) Influence of extracellular noradrenaline on the stimulationevoked secretion of noradrenaline from sympathetic nerves: evidence for a receptor-mediated feed-back inhibition of noradrenaline release. Naunyn Schmiedebergs Arch Pharmacol 275:11-23.

Starke K, Montel H, Gayk W, Merker R (1974) Comparison of the effects of clonidine on pre- and postsynaptic adrenoceptors in the rabbit pulmonary artery. alpha-Sympathomimetic inhibition of neurogenic vasoconstriction. Naunyn Schmiedebergs Arch Pharmacol 285:133-150.

Stern Y, Mayeux R, Cote L (1984) Reaction time and vigilance in Parkinson's disease. Possible role of altered norepinephrine metabolism. Arch Neurol 41:1086-1089.

Tai CH, Boraud T, Bezard E, Bioulac B, Gross C, Benazzouz A (2003) Electrophysiological and metabolic evidence that high-frequency stimulation of the subthalamic nucleus bridles neuronal activity in the subthalamic nucleus and the substantia nigra reticulata. FASEB J 17:1820-1830.

Vauquelin G, De Backer JP, Ladure P, Flamez A (1999) Identification of I1 and I2 imidazoline receptors in striatum membranes from different species. Ann NY Acad Sci 881:135-143.

Villegier AS, Drouin C, Bizot JC, Marien M, Glowinski J, Colpaert F, Tassin JP (2003) Stimulation of postsynaptic alphalb- and alpha2-adrenergic receptors amplifies dopamine-mediated locomotor activity in both rats and mice. Synapse 50:277-284.

Wang L, Kitai ST, Xiang Z (2006) Activity-dependent bidirectional modification of inhibitory synaptic transmission in rat subthalamic neurons. J Neurosci 26:7321-7327.

Wang R, Macmillan LB, Fremeau Jr RT, Magnuson MA, Lindner J, Limbird LE (1996) Expression of alpha 2-adrenergic receptor subtypes in the mouse brain: evaluation of spatial and temporal information imparted by $3 \mathrm{~kb}$ of $5^{\prime}$ regulatory sequence for the alpha $2 \mathrm{~A}$ AR-receptor gene in transgenic animals. Neuroscience 74:199-218.

Wellman PJ, Davies BT (1992) Effects of the alpha 1-adrenergic agonist cirazoline on locomotion and brown adipose tissue thermogenesis in the rat. Life Sci 50:1745-1753.

Xiang Z, Wang L, Kitai ST (2005) Modulation of spontaneous firing in rat subthalamic neurons by 5-HT receptor subtypes. J Neurophysiol 93:1145-1157.

Yamazaki M, Tanaka C, Takaori S (1979) Significance of central noradrenergic system on harmaline induced tremor. Pharmacol Biochem Behav 10:421-427.

Zhu ZT, Munhall A, Shen KZ, Johnson SW (2004) Calcium-dependent subthreshold oscillations determine bursting activity induced by $\mathrm{N}$-methylD-aspartate in rat subthalamic neurons in vitro. Eur J Neurosci 19:1296-1304.

Zhu ZT, Munhall A, Shen KZ, Johnson SW (2005) NMDA enhances a depolarization-activated inward current in subthalamic neurons. Neuropharmacology 49:317-327. 